BMJ Open

Diabetes

Research

\& Care

\section{Adverse effect of long work hours on incident diabetes in 7065 Ontario workers followed for 12 years}

To cite: Gilbert-Ouimet M, Ma $\mathrm{H}$, Glazier R, et al. Adverse effect of long work hours on incident diabetes in 7065 Ontario workers followed for 12 years. BMJ Open Diab Res Care 2018;6:e000496. doi:10.1136/ bmjdrc-2017-000496

Received 24 November 2017 Accepted 30 May 2018

Check for updates

${ }^{1}$ Axe santé des populations et pratiques optimales en santé, Centre de recherche FRQS du CHU de Québec, Québec, Canada

${ }^{2}$ Institute for Work \& Health, Toronto, Ontario, Canada ${ }^{3}$ Institute for Clinical Evaluative Sciences, Toronto, Ontario, Canada

${ }^{4}$ Dalla Lana School of Public Health, University of Toronto Toronto, Ontario, Canada ${ }^{5}$ Department of Family and Community Medicine, University of Toronto and St Michael's Hospital, Toronto, Ontario, Canada ${ }^{6}$ Centre for Urban Health Solutions, Li Ka Shing Knowledge Institute, St Michael's Hospital, Toronto, Ontario, Canada ${ }^{7}$ Département de médecine sociale et préventive, Université Laval, Québec, Canada ${ }^{8}$ Department of Epidemiology and Preventive Medicine, Monash University, Clayton, Victoria, Australia

Correspondence to Dr Mahée Gilbert-Ouimet; mahee.g.ouimet@gmail.com

\section{ABSTRACT}

Objective According to the International

Diabetes Federation, the most important challenge for prevention is now to identify social and environmental modifiable risk factors of diabetes. In this regard, long work hours have recently been linked with diabetes, but more high-quality prospective studies are needed. We evaluated the relationship between long work hours and the incidence of diabetes among 7065 workers over a 12year period in Ontario, Canada.

Research design and methods Data from Ontario respondents (35-74 years of age) to the 2003 Canadian Community Health Survey were prospectively linked to the Ontario Health Insurance Plan database for physician services and the Canadian Institute for Health Information Discharge Abstract Database for hospital admissions.

Our sample consisted of actively employed participants with no previous diagnoses of diabetes. Cox proportional hazard regression models were then performed to evaluate the relationship between long work hours ( $\geq 45$ hours per week) and the incidence of diabetes.

Results Long work hours did not increase the risk of developing diabetes among men. However, among women, those usually working 45 hours or more per week had a significantly higher risk of diabetes than women working between 35 and 40 hours per week (HR: 1.63 (95\% Cl 1.04 to 2.57$)$ ). The effect was slightly attenuated when adjusted for the potentially mediating factors which are smoking, leisure time physical activity, alcohol consumption and body mass index.

Conclusion Working 45 hours or more per week was associated with an increased incidence of diabetes among women, but not men. Identifying modifiable risk factors such as long work hours is of major importance to improve prevention strategies and orient policy making.

Diabetes is one of the primary causes of death worldwide, in addition to being a major risk factor for several other chronic diseases including cardiovascular diseases. ${ }^{1}$ By 2030 , an estimated 439 million adults will live with diabetes globally $(7.7 \%),{ }^{2}$ which will represent a $50 \%$ increase compared with $2010 .^{2}$ The global costs of this chronic disease are colossal, accounting for US\$1.31 trillion only for the year 2015. ${ }^{3}$ According to the International Diabetes Federation, the most

\section{Significance of this study}

What is already known about this subject?

- Long work hours have recently been linked with diabetes, but more high-quality prospective studies are needed.

What are the new findings?

- Evaluation of the relationship between long work hours and the incidence of diabetes among 7065 workers over a 12-year period in Ontario, Canada, showed increased risk of diabetes among women working 45 hours or more per week, but not among men.

How might these results change the focus of research or clinical practice?

- Promoting the regular workweek of 35-40 hours might be an effective strategy for preventing diabetes among women.

important challenge for prevention is now to identify social and environmental modifiable risk factors of diabetes. ${ }^{4}$ In this regard, long work hours have recently been linked with an increased incidence of diabetes among low (but not high) socioeconomic status individuals in a meta-analysis by Kivimäki et al. ${ }^{5}$ This estimate however relied exclusively on unpublished data where the methodological quality was not presented. ${ }^{67}$ Moreover, the meta-estimate based on results from the only four previously published studies led to a null finding, as mixed findings were observed in these studies despite their large sample sizes. ${ }^{8-11}$ More highquality prospective studies are needed.

The need to further investigate the effect of long working hours on diabetes incidence is further enhanced by the fact that three out of the four previous studies included only men $^{8}{ }^{10}$ or only women. ${ }^{9}$ It is increasingly recognized that single-sex studies in most areas of health are limited in their generalizability and quality, as they fail to take into account of how potential biological and 
social differences between men and women may influence the relationships between exposures and health outcomes. ${ }^{12}$ Specifically related to the area of long work hours and diabetes, it is plausible that the relationship may be stronger among women than men. Considering both paid and unpaid work, employed women are facing stiffer time constraints than men. ${ }^{13}$ Also, while men working long hours often hold high-skilled and well-paid occupations, ${ }^{14}$ women working such hours predominate in low-paid jobs. ${ }^{14}$ Working long work hours might lead to diabetes through a chronic stress response mechanism involving an acceleration of the hypothalamic-pituitary-adrenal activity boosting glucocorticoids and cortisol levels, ${ }^{15} 16$ and increasing the risk of endocrine abnormalities, insulin resistance, glucose intolerance, and obesity. ${ }^{17}$

The current study evaluated the relationship between long work hours and the incidence of diabetes among 7065 men and women over a 12-year period in Ontario, Canada.

\section{RESEARCH DESIGN AND METHODS}

\section{Data source and study population}

The data source for this study was the 2003 Canadian Community Health Survey (CCHS). Respondents' responses were linked to the Ontario Health Insurance Plan (OHIP) database covering physician services, as well as the Canadian Institute for Health Information Discharge Abstract Database (CIHI-DAD) for hospital admissions. These data sets were encoded and linked at the Institute for Clinical Evaluative Sciences. Information from the OHIP and CIHI-DAD databases was available up to March 31, 2015. The administrative databases were linked to the survey responses at the individual level, with the accuracy of the linkage verified against the Ontario Registered Persons Database using personal information provided by the respondents, such as health number, given names, surnames, date of birth, age, sex, and postal code.

The CCHS collects information on health conditions, health behaviors, and working conditions from representative cross-sectional samples of the Canadian population. The overall response rate from the respondents from Ontario to the 2003 CCHS was $78.5 \% .^{18}$ Of the 40507 Ontario respondents to the 2003 survey, 34950 $(86 \%)$ gave permission to be linked to administrative healthcare data. A successful linkage was obtained for 33679 of these respondents (96\%). For the purpose of this study, we focused on respondents who were currently employed, working 15 or more hours per week, and aged between 35 and 74 years $(n=8895)$.

\section{Outcome: incident diabetes}

Incident diabetes was defined as one hospital admission with a diabetes diagnosis, or two physician service claims with a diabetes diagnosis within a 2-year period. Excellent sensitivity and specificity have been reported for this algorithm, $86 \%$ and $97 \%$, respectively. ${ }^{19}$ Although the administrative data available in the OHIP database cannot distinguish between type 1 and type 2 diabetes, this restriction is unlikely to impact on our results given the high prevalence of type 2 diabetes, in particular among older cohorts, and the fact that the incidence of type 1 diabetes is very rare among adults. ${ }^{20}$

Since diabetes is known to affect work participation, ${ }^{21}$ cases occurring within the first 2 years of follow-up were removed to limit the possibility of reverse causation. This choice also resulted from the fact that our definition of diabetes required a 2-year period for physician claims. Respondents who did not develop diabetes within the first 2 years of follow-up were right-censored at the development of the disease, death from causes other than diabetes, or the end of the follow-up period (March 31, 2015).

\section{Primary independent variable: work hours}

The primary independent variable was self-reported usual work hours in the respondent's job per week and included both paid and unpaid hours. Work hours were grouped into the following categories: 15-34 hours, 35-40 hours, $41-44$ hours, and 45 or more hours per week. This categorization was performed to evaluate the potential adverse effects of working beyond the legal threshold of overtime (41 hours or more per week) of many countries including Canada, USA, China, and Greece. ${ }^{22}$

\section{Other independent variables}

Several other independent variables were also included in the analysis as covariates. Sociodemographic and health-related covariates measured were age; sex (men/ women); marital status (with/without a spouse) and presence of children under 12 in the house (yes/no); if the respondent was born in Canada; their ethnicity (white/ other); living location (urban/rural); and self-reported chronic medical conditions that have been diagnosed by a health professional and are expected to last or have lasted more than 6 months. Chronic medical conditions were divided into cardiovascular diseases, high blood pressure, back problems, mood and anxiety disorders, and other chronic conditions. A measure of whether a long-term physical or mental health condition limited the type or amount of activity the respondent could do at work (never, sometimes and often) was also included.

Other working conditions were also measured and were based on self-report and on occupational exposures imputed based on respondents' occupational title. Self-reported exposures included the number of weeks worked in the previous 12 months (1-26 weeks worked, 27-49 weeks, and 50 or more weeks), current shift schedule (regular, evening or night shift, rotating, or other shift schedules), and skills required to do the job (skills learned at the university, college, high school or learned on the job). Imputed occupational exposures based on occupational title included the primary type of posture or body movement required (primarily 
sitting; occupations involving primarily standing and/or walking; occupations involving combinations of sitting, standing, and walking; and work that involves other body postures) and the handling of loads $10 \mathrm{~kg}$ or greater (binary). Imputed exposures were assigned based on the validated Human Resources and Skills Development Canada's Career Handbook. ${ }^{23}$ The Career Handbook assigns various occupational exposures to occupations at the four-digit occupational level, equating to 520 different occupational titles. Each of these exposures was assigned by trained occupational analysts using a modified Delphi procedure. ${ }^{23}$

Body mass index (BMI) and health behaviors were also accounted for. BMI was based on self-reported height and weight (underweight/normal weight, overweight, obese). Health behaviors available were current smoking status (regular smoker, occasional smoker, non-smoker), alcohol consumption (non-drinker, regular drinker but never having five or more drinks in one sitting, regular drinker who has five or more drinks on an occasional to weekly status), and leisure time physical activity (inactive, moderately active, active).

\section{Analyses}

Of the original sample of 8895 respondents, 546 respondents $(6 \%)$ had pre-existing diabetes, identified either through self-report or through their healthcare record, leaving a sample of diabetes-free respondents of 8349 . Of this sample $566(7 \%)$ were missing information on working conditions, with an additional $610(7 \%)$ missing information on sociodemographic characteristics, health conditions or health behaviors, leaving a sample of 7173 ( $86 \%$ of original sample). From this sample we excluded respondents who developed diabetes in the first 2 years of follow-up ( $n=108)$, leaving a final analytic sample of 7065 respondents (figure 1). Logistic regression analyses examined the relationship between age, sex and our outcome with the probability of missing information on working conditions. Male respondents were more likely to be missing work information, but no relationship was observed between missing work information and age, or the development of diabetes over the study period. A subsequent logistic regression model examined the probability of missing other study variables. This model included age, sex, diabetes outcome, skill level and work hours. Female respondents in lower skilled occupations and those who developed diabetes over the follow-up period were more likely to be missing information on these characteristics. No relationship was observed between age and work hours and the probability of missing information.

Among the sample of 7065 respondents included in the analyses, we had 78390 person-years of follow-up, with a median length of follow-up in the sample of 11.7 years. Initial descriptive analyses examined the distribution of diabetes incidence rate and cumulative incidence across weekly work hours categories. Cox proportional hazard regression models were then performed to evaluate the relationship between long work hours and the incidence

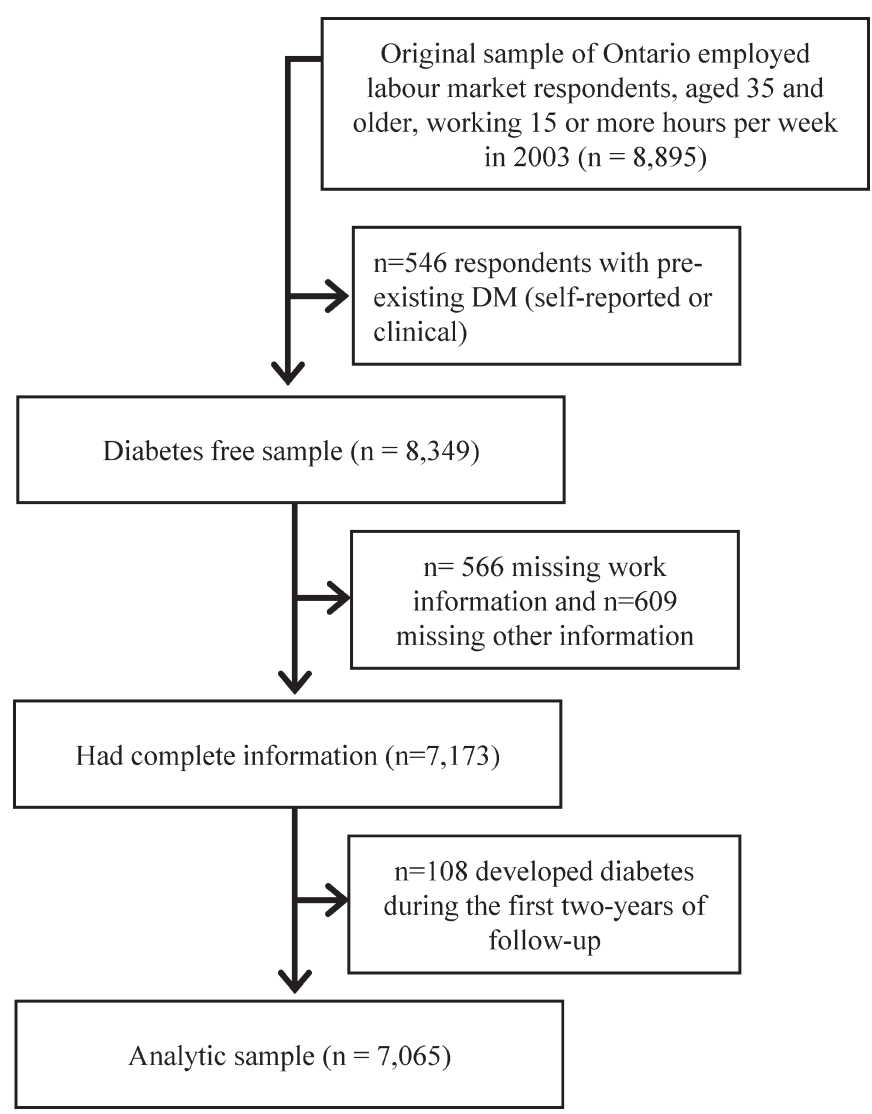

Figure 1 Flow chart. DM, diabetes mellitus.

of diabetes over the 12-year follow-up. The first model examined the effect of long work hours on diabetes after adjusting for age, weeks worked in the previous 12 months and skill level. A second model was additionally adjusted including all other covariates, except health behaviors and BMI, which were adjusted for in the third and fourth models, respectively. Health behaviors and BMI were sequentially adjusted for since it is not clear whether these factors are confounders or mediators in the relationship between work exposures and diabetes. Including potential mediators in the regression models could be considered overadjustment. ${ }^{24}$ All models were conducted separately for men and women. ${ }^{25}$ Differences between estimates from men and women were assessed by comparing the point estimates and the associated variances of these estimates for models run separately for men and women. ${ }^{26} 27$

To account for the complex sample design of the CCHS, in line with the guidelines from Statistics Canada, the CIs around each point estimate, with the exception of incidence rates per 1000 person-years, were adjusted using a bootstrap technique. ${ }^{18}$ All analyses were weighted to account for the probability of selection into the original sample and non-response. All analyses were conducted in SAS V.9.4.

\section{RESULTS}

Tables 1 and 2 present descriptive information for diabetes across usual weekly work hours categories for men and 
Table 1 Diabetes cumulative incidence (\%) and $95 \%$ Cls across weekly work hours categories, stratified by sex

\begin{tabular}{|c|c|c|c|c|}
\hline \multirow{3}{*}{$\begin{array}{l}\text { Total cumulative incidence of } \\
\text { diabetes }\end{array}$} & \multicolumn{2}{|c|}{ Women $(n=3502)$} & \multicolumn{2}{|c|}{ Men (n=3563) } \\
\hline & $\mathbf{n}$ & $\%(95 \% \mathrm{Cl})$ & $\mathbf{n}$ & $\%(95 \% \mathrm{Cl})$ \\
\hline & 263 & 7.5 (6.3 to 8.7$)$ & 436 & $12.2(10.6$ to 13.9$)$ \\
\hline \multicolumn{5}{|l|}{ Usual weekly work hours } \\
\hline $15-34$ & 65 & 7.9 (5.5 to 10.3$)$ & 28 & $17.6(8.4$ to 26.7$)$ \\
\hline $35-40$ & 110 & 6.8 (5.0 to 8.5$)$ & 223 & 14.6 (11.6 to 17.6$)$ \\
\hline $41-44$ & 12 & 7.2 (2.0 to 12.4$)$ & 32 & $12.0(6.3$ to 17.8$)$ \\
\hline$\geq 45$ & 76 & 8.5 (6.0 to 11.2$)$ & 153 & 9.5 (7.5 to 11.5$)$ \\
\hline \multicolumn{5}{|l|}{ Age group } \\
\hline $35-44$ years & 70 & 4.2 (2.9 to 5.6$)$ & 153 & 8.6 (6.6 to 10.6$)$ \\
\hline $45-54$ years & 119 & 9.1 (6.9 to 11.4$)$ & 223 & 13.9 (10.8 to 17.0$)$ \\
\hline $55-74$ years & 74 & 13.5 (9.9 to 17.1$)$ & 122 & 19.8 (14.7 to 25.0$)$ \\
\hline \multicolumn{5}{|l|}{ Body mass index } \\
\hline Underweight or normal weight & 61 & 7.0 (4.7 to 9.3$)$ & 94 & 8.6 (6.6 to 10.6$)$ \\
\hline Overweight & 96 & $8.4(6.5$ to 10.4$)$ & 190 & $13.9(10.8$ to 17.0$)$ \\
\hline Obese & 106 & 9.9 (5.2 to 14.6$)$ & 153 & 19.8 (14.7 to 25.0$)$ \\
\hline
\end{tabular}

Ontario respondents to the Canadian CommunityHealth Survey 2003.

women. Over the study period, $10 \%$ of the study population developed diabetes, with a higher incidence among men $(12.2 \%)$ than women $(7.5 \%)$, older groups, and obese individuals. Among women, a higher incidence of diabetes was observed among those working more than 40 hours per week compared with those working fewer hours. Conversely, among men, the incidence of diabetes rather tended to decrease as the number of work hours increased.

Table 3 provides the HRs of diabetes across work hours categories for men and women. Estimates were sequentially adjusted for age, weeks worked in the previous 12 months and the highest level of education (model 1), other sociodemographic characteristics, working conditions and health conditions (model 2), health behaviors (model 3), and BMI (model 4). No significant effect was observed among men, although the estimates tended to lower as the number of work hours increased, as observed in the descriptive analyses. Among women, those usually working 45 hours or more per week had a significantly higher risk of developing diabetes than women working

Table 2 Diabetes cumulative rate per 1000 personyears of follow-up and $95 \%$ Cls across weekly work hours categories, stratified by sex

\begin{tabular}{|c|c|c|c|c|}
\hline & \multicolumn{2}{|c|}{ Women $(n=3502)$} & \multicolumn{2}{|c|}{ Men $(n=3563)$} \\
\hline & $\mathbf{n}$ & Rate (95\% Cl) & $\mathbf{n}$ & Rate $(95 \% \mathrm{Cl})$ \\
\hline \multicolumn{5}{|c|}{ Usual weekly work hours } \\
\hline $15-34$ & 65 & 7.0 (5.5 to 9.0$)$ & 28 & 16.7 (11.7 to 23.9$)$ \\
\hline $35-40$ & 110 & 6.0 (4.9 to 7.2$)$ & 223 & $13.3(11.7$ to 15.1$)$ \\
\hline $41-44$ & 12 & 7.4 (5.4 to 10.2$)$ & 32 & 9.2 (7.4 to 11.5$)$ \\
\hline$\geq 45$ & 76 & 7.4 (5.5 to 9.9$)$ & 153 & 8.6 (7.2 to 10.4$)$ \\
\hline
\end{tabular}

between 35 and 40 hours per week (HR from model 2: 1.63 (95\% CI 1.04 to 2.57$)$ ). The effect was slightly attenuated when adjusted for the potentially mediating factors which are smoking, leisure time physical activity, alcohol consumption (model 3) and BMI (model 4).

\section{DISCUSSION}

Three out of the four previous studies on work hours and diabetes were limited by the inclusion of only men ${ }^{82}$ or women. ${ }^{9}$ The current 12-year prospective study added new evidence on the importance of evaluating this relationship separately for both genders. Working 45 hours or more per week was associated with an increased incidence of diabetes among women, but not men.

In line with our findings, Kroenke et at observed that working long hours led to an elevated risk of developing diabetes among women. These authors investigated whether the adverse effect was amplified among women having children or performing long hours of unpaid work outside employment. Surprisingly, no additional effect was observed within these subgroups. Recent evidence nonetheless suggested that assuming high family responsibilities may intensify the tendency of adults working long hours to engage in unhealthy behaviors ${ }^{29}$ experience difficulties with sleeping ${ }^{29}$ and have poor mental health. ${ }^{30}$ Perceiving a 'too high total workload' from both paid and unpaid work has also been linked to ill-health to a higher extent than performing long hours of paid work alone. ${ }^{31}$ In the current study, paid and unpaid hours spent on the job were measured, but unpaid hours performed outside of the employment were not. A post-hoc analysis examined whether living with children aged under 12 years modified the relationship between work hours 
Table 3 HRs and 95\% Cls for long work hours and incident diabetes over a 12-year follow-up ( $n=7065)$, stratified by sex

\begin{tabular}{|c|c|c|c|c|}
\hline & Model 1 & Model 2 & Model 3 & Model 4 \\
\hline & HR (95\% Cl) & HR (95\% Cl) & HR (95\% Cl) & HR (95\% Cl) \\
\hline \multicolumn{5}{|l|}{ Men } \\
\hline \multicolumn{5}{|c|}{ Usual weekly work hours } \\
\hline $15-34$ & $0.89(0.42$ to 1.87$)$ & 1.04 (0.48 to 2.24$)$ & 1.08 (0.51 to 2.30$)$ & 1.00 (0.48 to 2.10$)$ \\
\hline $35-40$ & Ref & Ref & Ref & Ref \\
\hline $41-44$ & 0.85 (0.47 to 1.53$)$ & $0.93(0.49$ to 1.75$)$ & 0.89 (0.47 to 1.67$)$ & 0.93 (0.51 to 1.70$)$ \\
\hline$\geq 45$ & $0.70(0.52$ to 0.95$)$ & 0.81 (0.59 to 1.11$)$ & 0.80 (0.59 to 1.10$)$ & $0.82(0.59$ to 1.14$)$ \\
\hline \multicolumn{5}{|l|}{ Women } \\
\hline \multicolumn{5}{|c|}{ Usual weekly work hours } \\
\hline $15-34$ & 1.06 (0.71 to 1.58$)$ & 1.10 (0.72 to 1.69$)$ & $1.11(0.72$ to 1.71$)$ & 1.11 (0.72 to 1.72$)$ \\
\hline $35-40$ & Ref & Ref & Ref & Ref \\
\hline $41-44$ & $1.19(0.51$ to 2.77$)$ & 1.13 (0.52 to 2.46$)$ & 1.14 (0.51 to 2.55$)$ & 1.05 (0.46 to 2.40$)$ \\
\hline$\geq 45$ & 1.56 (1.00 to 2.42$)$ & 1.63 (1.04 to 2.57$)$ & 1.58 (1.00 to 2.49$)$ & 1.51 (0.93 to 2.45$)$ \\
\hline
\end{tabular}

Ontario respondents to the Canadian CommunityHealth Survey 2003. Statistically significant estimates are in bold.

Model 1: adjusted for age, weeks worked in the previous 12 months and occupational skill level.

Model 2: additional adjustment for immigrant status, ethnicity, marital status, presence of children, activity restrictions at work, hypertension, arthritis, mood and anxiety, other chronic conditions, shift work, primary occupational body position, and handling of loads.

Model 3: additional adjustment for smoking, leisure time physical activity, and alcohol consumption.

Model 4: additional adjustment for body mass index.

Ref, reference.

and the risk of diabetes among sex. Unfortunately, the smaller sample size with this additional level of stratification led to wide CIs around risk estimates. Given this lack of precision, the results were not presented in the current paper (but are available on request), although the adverse effect of working 45 hours per week or more was most elevated among women living with children less than 12. Future studies, with larger samples, should further investigate the potentially amplifying effect of household responsibilities in the relationship between long work hours and diabetes, especially among women.

In the current study, the incidence of diabetes among men tended to diminish as work hours increased, although this trend did not reach statistical significance. This finding is consistent with that of Nakanishi et $a l^{10}$ showing a protective effect of working 8 hours or more per day on the incidence of diabetes among Japanese men. A first explanation for this finding could be a healthy workers selection effect, ${ }^{32}$ where an important proportion of men performing long work hours may be physically active at work and healthier than men working fewer hours. Supporting this hypothesis, more than a third of men working long hours in our sample $(36 \%)$ were holding jobs involving combinations of sitting, standing and walking. These occupations have previously been linked to a reduction in the risk of heart diseases among men. ${ }^{33}$ Other explanations could be that men tend to get an important sense of identity through work, ${ }^{30}$ many men working long hours hold high-skilled and well-paid occupations, ${ }^{14}{ }^{34}$ men who work long hours may have partners who work very few hours or not at all, and/or may be required to perform less unpaid work related to family/household responsibilities than women. ${ }^{35}$ Another previous Japanese study by Kawakami $e t a l^{8}$ however showed an increased risk of diabetes among men working more than 50 hours per week in an electrical company. ${ }^{8}$ During the 1-year observation period of this study, workers reported experiencing greater job demands and distress due to the rapid introduction of new automated production machines. The use of such technology could have contributed to the development of diabetes through pathways involving a reduction of physical activity during work hours ${ }^{36}$ or disturbances in glucose metabolism due to increases in blood pressure related to work stress. ${ }^{37}$

In their meta-analysis, Kivimäki et a $a \tilde{l}$ observed an increased risk of developing diabetes according to long working hours ( $\geq 55$ hours per week) in the low socioeconomic status group, while no increase was observed in the high socioeconomic status group (based on occupational titles). This finding can be due to the fact that workers in low socioeconomic groups tend to be more exposed to adverse physical and psychosocial work constraints. ${ }^{38}$ In the current study the modifying effect of occupational skill level was examined. Skill level was collapsed into three groups: high skill—requiring bachelor's education or higher; medium skill—requiring some postsecondary education; and low skill-requiring secondary or only on-the-job training. There were no meaningful differences in the relationship between work hours and risk of diabetes across skill level groups (results not shown but available on request). However, it is noteworthy that 
limited sample size in the lowest skill level group, that is, having only on-the-job training, prevented us from examining the relationship between work hours and the risk of diabetes among the lowest socioeconomic status group. This modifying effect should be further studied in both men and women, as it might contribute to enlighten sex/gender differences observed in the current study and in previous studies. ${ }^{9} 10$

The deleterious effect of long work hours observed among women of this study was robust to adjustment for sociodemographic and socioeconomic characteristics, other work-related exposures, and health conditions including hypertension, arthritis, and anxiety symptoms. However, risk estimates slightly attenuated with supplementary adjustments for smoking, leisure time physical activity, alcohol consumption (model 3) and BMI (model 4 ). Since these cofactors may be part of causal pathways linking long work works to diabetes (intermediate factors), adjusting for them could be considered as overadjustment. Further investigations of these causal pathways are required to quantify the direct and indirect trajectories linking work hours, potentially intermediate factors and diabetes. The potential intermediate effect of obesity would be especially important to study considering that it is a strong risk factor of diabetes in both men and women (HR from a large-scale meta-analysis ${ }^{39}: 5.13$ in men and 12.41 in women).

A few limitations of the current study need to be acknowledged. First, work hours were measured at a single time-point over the 12-year follow-up. Potential changes over time were thereby unaccounted for, which could have led to a potential misclassification bias. Such bias generally leads to an underestimation of the true effect. Second, it was not possible to distinguish type 1 and type 2 diabetes in the administrative healthcare records. It has however been estimated that type 1 diabetes represents approximately only $5 \%$ of all cases in those 18 years old or older. ${ }^{40}$ Third, the administrative healthcare records used to capture diabetes require a medical diagnosis of diabetes. The number of cases has likely been underestimated due to undiagnosed cases. However, it has been estimated that over a 5-year period, more than $70 \%$ of Ontarians aged over 40 receive a serum blood glucose test. ${ }^{41}$ In addition, Ontario has a publicly funded healthcare system, which limits socioeconomic differences in access to general practitioner care. ${ }^{42}$ The use of biological measures (such as glycated hemoglobin or blood glucose tolerance tests) would have allowed a more thorough identification of diabetes cases, although financial and logistical constraints would likely have led to a smaller and potentially less generalizable sample than the population survey sample that we were able to use in this study. Also, healthcare records offered the advantage of accurately estimating the time between baseline interview and diabetes diagnosis, rather than relying on the time between study measurements ${ }^{8-10}$ or evaluating the prevalence at follow-up, ${ }^{11}$ as seen in the previous studies on work hours and biologically measured diabetes.
Additional strengths of the current study include the use of a large sample representative of the general Ontarian working population and including $50 \%$ women, a good participation rate $(78.5 \%)$, a long follow-up period (over 12 years), and the consideration of several confounders. A further strength is the use of an objective measure of diabetes, which limits the potential for common method bias to inflate the effects. These strengths allowed the current study to go beyond existing knowledge by circumventing previous studies' limitations, and therefore provided new insights about the effect of work hours on the development of diabetes in men and women.

\section{CONCLUSIONS}

Using a sample that is representative of the variety of occupations and industries of the Canadian labor market, the current study suggests that working 45 hours or more per week was associated with an increased incidence of diabetes among women. Considering the rapid and substantial increase of diabetes prevalence in Canada and worldwide, identifying modifiable risk factors such as long work hours is of major importance to improve prevention and orient policy making, as it could prevent numerous cases of diabetes and diabetes-related chronic diseases. Future studies documenting the pathways linking work hours, health behaviors, family responsibilities and diabetes and related gender differences are nevertheless needed to gain a better understanding of the effects and enrich prevention strategies.

Contributors MG-0 and PS designed the study, generated the hypotheses, and wrote the first draft. All authors contributed to the interpretation of the data and critically reviewing the paper, and approved the final version. HM did the analyses. HM had full access to anonymized data from the 2003 Canadian Community Health Survey (CCHS), the Ontario Health Insurance Plan (OHIP) database, as well as the Canadian Institute for Health Information Discharge Abstract Database (CIHI-DAD) for hospital admission. MG-0 is the guarantor of this work.

Funding This work was supported by the Canadian Institutes of Health Research (CIHR), and by the Institute for Clinical Evaluative Sciences (ICES), which is funded by an annual grant from the Ontario Ministry of Health and Long-Term Care (MOHLTC). The opinions, results and conclusions reported in this paper are those of the authors and are independent from the funding sources. No endorsement by ICES or the Ontario MOHLTC is intended or should be inferred. Parts of this material are based on data and information compiled and provided by the Canadian Institute for Health Information (CIHI). However, the analyses, conclusions, opinions and statements expressed herein are those of the authors and not necessarily those of the $\mathrm{CIHI}$. PS was supported by a Research Chair in Gender, Work and Health from the Canadian Institutes for Health Research (CIHR). RG was supported as a Clinician Scientist in the Department of Family and Community Medicine at the University of Toronto and at St Michael's Hospital. MGO held a CIHR research grant for her postdoctoral fellowship.

Conflicts of interest None declared.

Patient consent Not required.

Ethics approval Approval for the secondary data analyses was obtained through the University of Toronto, Health Sciences Ethics Committee.

Provenance and peer review Not commissioned; externally peer reviewed. Data statement The linked data used for this study is held securely in coded form at the Institute for Clinical Evaluative Sciences (ICES). ICES is a not-for-profit research institute encompassing a secure and accessible array of Ontario's healthrelated data. While data sharing agreements prohibit ICES from making the data set publicly available, access may be granted to those who meet pre-specified criteria for confidentialaccess, available at www.ices.on.ca/DAS. Data will be made 
available to interested researchers in the same fashion in which it was made available to the authors.

Open access This is an Open Access article distributed in accordance with the Creative Commons Attribution Non Commercial (CC BY-NC 4.0) license, which permits others to distribute, remix, adapt, build upon this work non-commercially, and license their derivative works on different terms, provided the original work is properly cited and the use is non-commercial. See: http://creativecommons.org/ licenses/by-nc/4.0/

C) Article author(s) (or their employer(s) unless otherwise stated in the text of the article) 2018. All rights reserved. No commercial use is permitted unless otherwise expressly granted.

\section{REFERENCES}

1. NCD Risk Factor Collaboration (NCD-RisC). Worldwide trends in diabetes since 1980: a pooled analysis of 751 population-based studies with 4.4 million participants. Lancet 2016;387:1513-30.

2. Shaw JE, Sicree RA, Zimmet PZ. Global estimates of the prevalence of diabetes for 2010 and 2030. Diabetes Res Clin Pract 2010;87:4-14

3. Bommer C, Heesemann E, Sagalova V, et al. The global economic burden of diabetes in adults aged 20-79 years: a cost-of-illness study. Lancet Diabetes Endocrinol 2017;5:423-30.

4. International Diabetes Federation. Les déterminants sociaux du diabète et le défi de la prévention. 2015. http://www.idf.org/ diabetesatlas $/ 5 \mathrm{e} / \mathrm{fr} /$ determinants-sociaux?language $=\mathrm{fr}$.

5. Kivimäki M, Virtanen M, Kawachi I, et al. Long working hours, socioeconomic status, and the risk of incident type 2 diabetes: a meta-analysis of published and unpublished data from 222120 individuals. Lancet Diabetes Endocrinol 2015;3:27-34

6. Godin K, Stapleton J, Kirkpatrick SI, et al. Applying systematic review search methods to the grey literature: a case study examining guidelines for school-based breakfast programs in Canada. Syst Rev 2015;4:138.

7. Cochrane. General methods for Cochrane reviews. Version 5.1.0 [updated March 2011]. Editors: Julian PT Higgins and Sally Green. 2011. http://handbook.cochrane.org/chapter_10/10_3_2_including unpublished_studies_in_systematic_reviews.htm.

8. Kawakami N, Araki S, Takatsuka N, et al. Overtime, psychosocial working conditions, and occurrence of non-insulin dependent diabetes mellitus in Japanese men. $J$ Epidemiol Community Health 1999;53:359-63.

9. Kroenke $\mathrm{CH}$, Spiegelman D, Manson J, et al. Work characteristics and incidence of type 2 diabetes in women. Am J Epidemiol 2007;165:175-83

10. Nakanishi N, Nishina K, Yoshida H, et al. Hours of work and the risk of developing impaired fasting glucose or type 2 diabetes mellitus in Japanese male office workers. Occup Environ Med 2001;58:569-74.

11. Eriksson AK, van den Donk M, Hilding $A$, et al. Work stress, sense of coherence, and risk of type 2 diabetes in a prospective study of middle-aged Swedish men and women. Diabetes Care 2013;36:2683-9.

12. Schiebinger $L$. Scientific research must take gender into account. Nature 2014;507:9.

13. ElfG E, Index GE. Measuring gender equality in the European union 2005-2012. Publications office of the European union, 2015. 2015.

14. Wilkins R, Wooden M. Two decades of change: the australian labour market 1993-2013. Aust Econ Rev 2014:47:417-31.

15. Lupien SJ, McEwen BS, Gunnar MR, et al. Effects of stress throughout the lifespan on the brain, behaviour and cognition. Nat Rev Neurosci 2009:10:434-45.

16. McEwen BS, Bowles NP, Gray JD, et al. Mechanisms of stress in the brain. Nat Neurosci 2015;18:1353-63.

17. Siddiqui A, Madhu SV, Sharma SB, et al. Endocrine stress responses and risk of type 2 diabetes mellitus. Stress 2015;18:498-506.

18. Canada S. User Guide to the 2003 Canadian Community Health Survey. 82M0013GPE. 2005. Ottawa, ON: Statistics Canada, 2003.
19. Hux JE, Ivis F, Flintoft V, et al. Diabetes in Ontario: determination of prevalence and incidence using a validated administrative data algorithm. Diabetes Care 2002;25:512-6.

20. American Diabetes Association. Diagnosis and classification of diabetes mellitus. Diabetes Care 2005;28 Suppl 1:S37-S42.

21. Vijan S, Hayward RA, Langa KM. The impact of diabetes on workforce participation: results from a national household sample. Health Serv Res 2004;39-1653-70.

22. Roozedaal WL, Hoekstra RF. Working hours and overtime: balancing economic interests and fundamental rights in a globalized Economy. Edited by the International Labour and Employment Relations Association (ILERA). 2015. https://www.ilera2015.com/dynamic/full/ IL186.pdf.

23. Canada H. National occupational classification career handbook: 2 nd Edition. LM-410-05-03E. Ottawa, ON: Government of Canada, 2011.

24. Schisterman EF, Cole SR, Platt RW. Overadjustment bias and unnecessary adjustment in epidemiologic studies. Epidemiology 2009;20:488-95.

25. Kautzky-Willer A, Harreiter J, Pacini G. Sex and gender differences in risk, pathophysiology and complications of type 2 diabetes mellitus. Endocr Rev 2016;37:278-316.

26. Austin PC, Hux JE. A brief note on overlapping confidence intervals. $J$ Vasc Surg 2002:36:194-5.

27. Wolfe R, Hanley J, different If we're so. why do we keep overlapping? When 1 plus 1 doesn't make 2. Can Med Assoc J 2002:65-6.

28. Nakanishi N, Yoshida H, Nakamura K, et al. Alcohol consumption and risk for hypertension in middle-aged Japanese men. $J$ Hypertens 2001;19:851-5.

29. Artazcoz L, Borrell C, Cortas I, et al. Occupational epidemiology and work related inequalities in health: a gender perspective for two complementary approaches to work and health research. $J$ Epidemiol Community Health 2007;61(Supplement 2):ii39-ii45.

30. Dinh H, Strazdins L, Welsh J. Hour-glass ceilings: workhour thresholds, gendered health inequities. Soc Sci Med 2017;176:42-51.

31. Krantz G, Berntsson L, Lundberg U. Total workload, work stress and perceived symptoms in Swedish male and female white-collar employees. Eur J Public Health 2005;15:209-14.

32. Checkoway H, Pearce NE, Kriebel D. Research methods in occupational epidemiology. Second edition. New York: Oxford University Press, 2004:372.

33. Smith $\mathrm{P}, \mathrm{Ma} \mathrm{H}$, Glazier $\mathrm{RH}$, et al. The relationship between occupational standing and sitting and incident heart disease over a 12-Year period in Ontario, Canada. Am J Epidemiol 2018;187:27-33.

34. Cha Y, Weeden KA. Overwork and the slow convergence in the gender gap in wages. Am Sociol Rev 2014;79:457-84.

35. OCDE. Time use across the world. Gender data portal. 2016. https:// www.oecd.org/gender/data/balancingpaidworkunpaidworkandle isure.htm

36. Emdin CA, Rahimi K, Neal B, et al. Blood pressure lowering in type 2 diabetes: a systematic review and meta-analysis. JAMA 2015;313:603-15.

37. Gilbert-Ouimet M, Trudel X, Brisson C, et al. Adverse effects of psychosocial work factors on blood pressure: systematic review of studies on demand-control-support and effort-reward imbalance models. Scand J Work Environ Health 2014;40:109-32.

38. In: Siegrist J, Marmot M, e al, eds. Social inegalities in health, new evidence and policy implications. Oxford University Press: Oxford, 2006

39. Guh DP, Zhang W, Bansback N, et al. The incidence of comorbidities related to obesity and overweight: a systematic review and meta-analysis. BMC Public Health 2009;9:88.

40. Inserm. 2014. Dossier réalisé en collaboration avec le Pr Christian Boitard, directeur de recherche l'Inserm et diabétologue l'hôpital Cochin,. Paris. http://wwwinsermfr/thematiques/physiopathologiemetabolisme-nutrition/dossiers-d-information/diabete-de-type-1did.

41. Wilson SE, Lipscombe LL, Rosella LC, et al. Trends in laboratory testing for diabetes in Ontario, Canada 1995-2005: a populationbased study. BMC Health Serv Res 2009;9:41.

42. Glazier RH, Agha MM, Moineddin R, et al. Universal health insurance and equity in primary care and specialist office visits: a populationbased study. Ann Fam Med 2009;7:396-405. 